\title{
The College archives
}

\section{Records of standing committees}

\author{
Margaret Harcourt Williams
}

For the College in the late 20th century standing committees are an essential part of the administrative structure, but the system of committees meeting regularly with responsibility for particular areas of work developed only towards the end of the 19th century. For its first 50 years or so the work of the Medico-Psychological Association (MPA) (forerunner of the College) was carried out by the Officers and Council, who reported to Annual and Council Meetings.

The standing committee best represented in the College archives is the Education (originally called the Educational) Committee. An Education Committee or Board of Education was established at the 1892 Annual Meeting; membership was open to all MPA Members who were teachers of psychological medicine in universities or medical schools, although in practice the committee was not very large. Minutes from 1893 to 1971 are in the archives. With the minutes are question papers and regulations for the certificates and diplomas in psychological medicine administered by the (Royal)MPA and for the nursing examinations it ran until the 1950s. These have been used both by College Members and external enquirers for their research. The archives also include minutes of Education Committee sub-committees from the 1950s to 1970s, namely the Clinical Tutors, Films, General Purposes and Mental Nursing Sub-Committees; the Film Sub-Committee records also include lists and descriptions of psychiatric films.

The Parliamentary Committee developed from the Lunacy Legislation Watch Committee of 1877 so can be considered the oldest standing committee. The archives contain a long series of its minutes, although unfortunately these do not begin until 1906. The archivist would welcome any suggestions on the possible whereabouts of earlier minutes. Despite the title, the main work of this committee in the early part of this century concerned asylum officers' pensions and working conditions.

A Library Committee was first suggested in 1877, the development of a circulating library having been suggested as a suitable use for the MPA's surplus funds. A Standing Committee was established in 1896 after the MPA received a large bequest of books from Dr Daniel Hack Tuke. The only record of this Committee is a minute book from 1904-1951, by which time there was no suggestion of 'surplus funds' being available and in which the topics under discussion, for example library accommodation and security, and the late return or disappearance of books, sound very familiar.

The RMPA also had a Standing Papers and Discussions Committee from 1946, and a Public Relations Committee, established in 1957 "to study the education of the Public and Press in Mental Health Matters", minutes of which are in the archives.

A Standing Research and Clinical Committee was established in 1927, although there had been a Research Committee in 1914. Minutes of the Standing Committee exist but are not at present in the archives.

The RMPA did not have a standing editorial or finance committee. Both the Editor and Treasurer reported to Council and Annual meetings, and the Editor had the help of assistant editors, an editorial board and occasional special committees, including the alarming sounding Journal Delays Committee of 1897. There are no known RMPA editorial or financial records.

Minutes of the Education and Parliamentary Committees have been abstracted on to the College's Meetings Database. Please ask the archivist if you would like to use this or to consult the archives. 